\title{
Dietary Supplementation of Leucine in Premating Diet Improves the Within-Litter Birth Weight Uniformity, Antioxidative Capability, and Immune Function of Primiparous SD Rats
}

\author{
Ting Liu $(\mathbb{D}$, Bin Zuo, Wei Wang, Shilan Wang, and Junjun Wang \\ State Key Laboratory of Animal Nutrition, College of Animal Science and Technology, China Agricultural University, \\ Beijing 100193, China \\ Correspondence should be addressed to Junjun Wang; jkywjj@hotmail.com
}

Received 14 January 2018; Accepted 13 March 2018; Published 18 April 2018

Academic Editor: Lidong Zhai

Copyright (C) 2018 Ting Liu et al. This is an open access article distributed under the Creative Commons Attribution License, which permits unrestricted use, distribution, and reproduction in any medium, provided the original work is properly cited.

\begin{abstract}
The high within-litter birth weight variation has become a big issue in multiparous animals. The present study was conducted to investigate the effects of leucine supplementation in premating diet on the reproductive performance, maternal antioxidative capability, and immune function in primiparous rats. Six-week-old female SD rats were assigned to basal diet or $0.6 \%$ leucine supplemented diet for two weeks. After mating during the eighth week of age, the rats were fed with regular gestation diet. Maternal blood samples were collected on the day before mating (day -1) and day 7 and day 20 of pregnancy, while ovaries and uteruses were obtained on day -1 and on day 7 , respectively. The results indicate that, compared with control group, within-litter birth weight variation was significantly decreased, while birth weights were significantly increased in the leucine group $(P<0.01)$. Also, leucine improved the embryo distribution uniformity and the number of implantation sites in uterine. The ovarian gene expressions of LHR, CYP19A1, and VEGFA were upregulated, while Mucin-1 was decreased significantly $(P<0.05)$. Leucine also increased the maternal antioxidant capacity and immune function. Conclusively, leucine supplementation in premating diet could improve the reproductive performance, which could be attributed to the improved oxidative and immune status.
\end{abstract}

\section{Introduction}

Over the past few decades, advances in selecting and breeding have significantly increased the litter sizes in modern highproducing sows [1]. However, this increase in litter size has coincided with an enlarged number of growth retarded piglets and increased preweaning mortality and heterogeneity at ten weeks of age $[2,3]$, and these losses can be partly attributed to the increased proportion of piglets of low birth weight. Importantly, the increased preweaning mortality is likely the result of the high within-litter birth weight variation $[1,4]$. During the peri-implantation period, conceptuses can show different stages in elongation process in uterus [5], indicating that the diversity of developmental ability of conceptuses may lead to the variation in fetal growth [6] and decrease the birth weight uniformity of littermates. Considering the fact that the oocyte quality is the main factor affecting early embryonic survival and fetal development [7], nutritional interventions during the follicular growth period may decrease within-litter birth weight variation. In addition, maternal physiology condition, especially antioxidative capability and immune function, acts as a potential influence factor for the pregnancy results. It has been reported that a balance between reactive oxygen species (ROS) and antioxidant not only plays a great role in hormone secretion of ovary, but also benefits oocyte maturation and quality [8-10]. Also, some other researches indicated that maternal immune system influences reproductive event, particularly around the time of conception and embryo implantation [11], and immune dysregulation is implicated in adverse perinatal health outcomes [12].

Leucine, like other essential nutrients required for maintaining life in rodent [13], needs to be supplemented in diet because animals cannot synthesize it by themselves [14]. Leucine metabolism has been largely reported to be closely associated with early-state embryo development by activating the mTOR signal pathway $[15,16]$. Besides, as 
a prerequisite for fetus growth, leucine has an important function in blastocyst development, which may further contribute to embryo implantation [17]. It has been proven that leucine could trigger trophectoderm motility and upregulate blastocyst outgrowth in the peri-implantation period in vitro $[18,19]$, eventually improving the success rate of mouse embryonic implantation. However, to our knowledge, the effects of leucine supplementation during the follicular growth period on the outcome of pregnancy are rarely investigated. We hypothesized that leucine supplementation during preconception period facilitates oocyte maturation and promotes embryonic implantation uniformity during the peri-implantation period, ultimately increasing the littermate birth weight uniformity. To this aim the present study was conducted to investigate the effects of leucine administration in premating diet on within-litter birth weight variation, maternal antioxidative capability, and immune function in primiparous SD rats.

\section{Materials and Methods}

2.1. Animals. Sprague-Dawley female rats aged five weeks were purchased from Sibeifu Inc (Beijing, China). Upon arrival, there was one week for adaptation. They were housed in individual cages in a climatized environment at $23^{\circ} \mathrm{C}$ in a room with a $12 \mathrm{~h}$ light $/ 12 \mathrm{~h}$ dark cycle (lights on from 8:00 am to $8: 00 \mathrm{pm}$ ) and were given free access to water and feed. All animal procedures were approved by the China Agricultural University Institution Animal Care and Use Committee.

2.2. Diet and Experimental Design. The experimental groups contain a control group (basal diet for adult rodent) and a leucine group (basal diet supplemented with 0.6\% 1-Leucine), and the treatment lasted for two weeks from six to eight weeks of age. After two weeks of leucine administration, each female rat was cocaged with one male SD rat proven fertile overnight, and the presence of spermatozoa in the vaginal smear in the next morning was defined as day 1 of pregnancy. Females that did not mate were reintroduced to males and daily leucine manipulation was repeated until mating was achieved. Mating had been attempted for a maximum of 2 nights, with those that did not mate being excluded from the study.

2.3. Plasma and Tissue Sampling. At the end of the leucine administration, the day before mating was defined as day -1 , 10 dams from each group were anesthetized with sodium pentobarbital and then sacrificed 5 min later. Ovary and uterus were immediately snap-frozen in liquid nitrogen and stored in $-80^{\circ} \mathrm{C}$ for quantification of gene expression and determination of the immune function. Liver tissue was collected for antioxidant capacity analysis. On day 7 of pregnancy, at which point the embryo establishes contact with the uterine endothelium, 10 dams from each group were anesthetized and killed. After exposing the uterine horns, the implantation sites were counted and collected. In addition, considering the effect of birth order, specifically the uncertainty of delivery time and the intake of colostrum on fetal body weight, the remaining pregnant rats ( $n=12$ /group) were sacrificed to evaluate the within-litter birth weight variation on day 20 of gestation (duration of pregnancy is $21-23$ days). On day -1 and days 7 and 20 of pregnancy, blood was collected from the vena cava into heparinized vacuum blood tube for analysis of amino acids, hormone, and metabolites concentration. Blood samples were centrifuged at 3,000 rpm for $15 \mathrm{~min}$ and stored at $-20^{\circ} \mathrm{C}$.

2.4. Biochemical Analysis. Plasma concentrations of insulin, insulin-like growth factor 1 (IGF-1), estradiol, progesterone, luteinizing hormone (LH), and follicle stimulating hormone (FSH) were analyzed by radio immunoassay kits. The levels of plasma immunoglobulins ( $\operatorname{IgA}, \operatorname{IgG}$, and $\operatorname{IgM}$ ), interleukins (IL-1 $\beta$ and IL-6), and tumor necrosis factor $\alpha$ (TNF $\alpha$ ) were measured using commercial ELISA kits for rats. Redox-status-related parameters including malondialdehyde (MDA), superoxide dismutase (SOD), glutathione peroxidase (GSH-Px), and catalase (CAT) in liver were determined using enzyme immunoassay kits. All the assay kits were purchased from Sino-UK Inc (Beijing, China) and processed following the instructions provided by the manufacturer. Concentrations of amino acids in plasma were determined by a high-performance liquid chromatography (HPLC) involving precolumn derivatization with $o$-phthaldialdehyde $[20,21]$.

2.5. RNA Extraction and Quantitative Real-Time PCR Analysis. The RNA extraction from implantation sites was performed using the TRIzol reagent (CWBIO, China) according to the manufacturer's protocol, and the total RNA concentration and purity were evaluated using NanoDrop spectrophotometer (Thermo Scientific, USA). A total of $1.0 \mu \mathrm{g}$ RNA was reverse transcribed to complementary DNA (cDNA) using RevertAid 1st Strand cDNA Synthesis Kit (Thermo, USA). Then cDNA was used for amplifying by specific primers (Supplementary Table 1) using SYBR Green (Takara, Japan) with an Applied Biosystems 7500 Real-Time PCR System (ABI, USA). The PCR system consisted of $5.0 \mu \mathrm{L}$ of SYBR Green qPCR mix, $1.0 \mu \mathrm{L}$ of $\mathrm{cDNA}, 1.0 \mu \mathrm{L}$ of primer pairs $(0.5 \mu \mathrm{L}$ forward and $0.5 \mu \mathrm{L}$ reverse), and $3.0 \mu \mathrm{L}$ of double distilled water with a total volume of $10.0 \mu \mathrm{L}$. The protocols for gene quantification included a denaturation program (10 min at $95^{\circ} \mathrm{C}$ ) and amplification and quantification program repeated for 40 cycles $\left(15 \mathrm{~s}\right.$ at $95^{\circ} \mathrm{C}, 60 \mathrm{~s}$ at $\left.60^{\circ} \mathrm{C}\right)$, followed by a melting curve program at $60-95^{\circ} \mathrm{C}$ with a heating rate of $0.1^{\circ} \mathrm{C}$ per second and continuous fluorescence measurement. Data were analyzed using the $2^{-\Delta \Delta \mathrm{ct}}$ method as described [22].

2.6. Statistical Analysis. Values were expressed as means \pm SEM. Effects of leucine on the outcome of pregnancy were analyzed using a Student's unpaired $t$-test (GraphPad Prism version 7.0). $P<0.05$ was considered significantly different, and $0.05<P<0.1$ was considered a tendency.

\section{Results}

3.1. Reproductive Performance. In the present study, there is no statistical difference in average daily feed intake between the control and leucine supplementation group (Table 1). 
TABLE 1: Effect of dietary leucine supplementation on average daily feed intake during premating and pregnancy in primiparous SD rats.

\begin{tabular}{lccc}
\hline Items & Control & $0.6 \%$ leucine & $P$ value \\
\hline Average daily feed intake $(\mathrm{g})$ & & & \\
Premating & $16.87 \pm 0.30$ & $17.96 \pm 0.38$ & 0.314 \\
Pregnancy & $20.64 \pm 0.32$ & $21.74 \pm 0.32$ & 0.909 \\
\hline
\end{tabular}

Value is the mean \pm standard error of means of twelve replicates.

Fetal birth weight was indicated as body weight at late gestation (day 20 of pregnancy). Variation of within-litter birth weight was determined as a coefficient of littermate birth weight. The reproductive outcomes were presented in Table 2. In the leucine group, within-litter birth weight variation was significantly downregulated, compared to the control group $(P<0.05)$. At the same time, litter weight in the leucine supplemented group was higher $(P<0.01)$ than that in the control group. In addition, placental weight was significantly higher $(P<0.05)$ in the leucine group. There was no difference in litter size between the two groups. In the early gestational stage, embryonic implantation was investigated on day 7 of pregnancy, during which blastocysts establish contact with endometrium. There was no difference in total number of implantation sites (Table 3). Extreme embryo distribution in two uterine horns indicated by the number of implantation sites was only observed in the control group (Figure 1). No statistical difference was found in body weight on day -1 of pregnancy (Table 4 ), whereas the relative weight of uterus was higher $(P<0.01)$ in the leucine group when compared to the control group. Although the absolute weight of the ovary was higher $(P<0.05)$ in the leucine group, the relative weight did not differ between these two groups (Table 4).

3.2. Hormone Concentration. Maternal plasma reproductive hormone concentrations were presented in Table 5. Compared with the control group, both the IGF-1 and estradiol level were higher at all the tested time points during pregnancy (all $P<0.05$ ) in the leucine group. In addition, insulin level was reduced $(P<0.05)$, while LH concentration was higher $(P<0.05)$ on day -1 of pregnancy, progesterone concentration was upregulated $(P<0.05)$ on day 7 of pregnancy, and FSH level was higher $(P<0.05)$ on day 20 of pregnancy by supplementing leucine in the diet.

3.3. Gene Expression. On day -1 of pregnancy, ovarian receptivity-related gene expressions were determined by quantitative real-time PCR. Leucine supplementation upregulated the expression of LSHR (Figure 2(a)), CYP19A1 (Figure 2(d)), and VEGFA (Figure 2(e)), while it downregulated Mucin-1 (Figure 2(f)). No statistical difference was found in expression of FSHR (Figure 2(b)) and CYP17A1 (Figure 2(c)) between the two groups.

3.4. Antioxidative Capability. Effect of leucine on the antioxidant enzyme activity and oxidant products on day -1 of pregnancy were presented in Table 6. Leucine administration upregulated the level of SOD $(63.02 \pm 1.10$ and $51.29 \pm 2.60$, leucine and control group, resp., $P<0.01$ ), and it also upregulated CAT and GSH-Px concentrations in plasma $(P<$ $0.05)$. Besides, the level of CAT in liver from the leucine group $(58.66 \pm 1.29)$ was higher than that in the control group $(53.52 \pm 3.20)(P<0.05)$. There was no difference on MDA concentration in both plasma and liver.

3.5. Immune Function. There was a marked effect of leucine on the level of immunoglobulin (Figure 3(a)) and inflammatory cytokines in the plasma (Figure 3(b)). Supplementation of leucine upregulated the plasma concentrations of IgM, IL$1 \beta$, IgG, and IL- 6 concentrations $(P<0.05)$ on day -1 of pregnancy. Dietary leucine administration did not affect the plasma level of IgA and TNF $\alpha$ on day -1 of pregnancy.

3.6. Amino Acids Profile. On day -1 of pregnancy, leucine supplementation significantly upregulated the plasma concentration of alanine, glutamine, arginine, leucine $(P<0.05)$, and aspartic acid $(P<0.01)$. Plasma phenylalanine and isoleucine showed a trend to increase $(P<0.10)$. But leucine had no effect on those of other measured amino acids, including cysteine, glycine, glutamic acids, methionine, lysine, tyrosine, proline, tryptophan, serine, threonine, asparagine, valine, and histidine, as compared with the control group (Table 7). On day 7 of pregnancy, only plasma aspartic acids showed a lower level $(P<0.05)$ than control group, while methionine concentrations had a trend to increase $(P<0.10)$ and the level of tryptophan trended to decrease $(P<0.10)$ in the leucine group (Table 7).

\section{Discussion}

Currently, special attention has been given to high variation of within-litter birth weight in modern prolific sows, which is characterized with a higher proportion of low birth weight newborns $[23,24]$ and their poor postnatal survival and subsequent growth performance [1]. Leucine has been largely reported to play key roles in oocyte maturation and early embryo development [19]. In the present study, our results demonstrate that leucine supplementation in the premating diet decreases the within-litter birth weight variation, and the increased embryonic implantation uniformity in two uterine horns and more appropriate strategies of amino acids utilization could partially explain the effect of leucine supplementation on neonatal outcomes. Besides, better body physiology condition, as shown by the increased antioxidative capability and immune function, may also contribute to improving the maternal phenotype.

One potential way to reduce within-litter variation of birth weight is nutritional interventions in premating period, because it has been demonstrated that diet composition fed before insemination can affect the distribution of fetal size within a litter [25]. In the current study, fetuses of leucine supplementation group show better within-litter birth weight uniformity than that in the control group, concomitant with increased litter weight. Consistent with the previous findings, it has been shown in pig that nutritional manipulation before 
TABLE 2: Effect of dietary leucine supplementation on the reproductive performance in primiparous SD rats.

\begin{tabular}{lccc}
\hline Items & Control & $0.6 \%$ leucine & $P$ value \\
\hline Within-litter birth weight variation (\%) & $6.04 \pm 0.01^{*}$ & $5.30 \pm 0.01$ & 0.036 \\
Number of live-born rats $(n)$ & $14.33 \pm 0.28$ & $16.00 \pm 0.42$ & 0.195 \\
Average birth weight of live-born rats $(g)$ & $1.97 \pm 0.01$ & $2.12 \pm 0.04^{* *}$ & $<0.01$ \\
Average weight of placentas $(g)$ & $0.45 \pm 0.01$ & $0.56 \pm 0.03^{*}$ & 0.021 \\
\hline
\end{tabular}

Value is the mean \pm standard error of means of twelve replicates; $*$ is means labeled with significant difference $(P<0.05) ; * *$ is means labeled with extreme difference $(P<0.01)$.
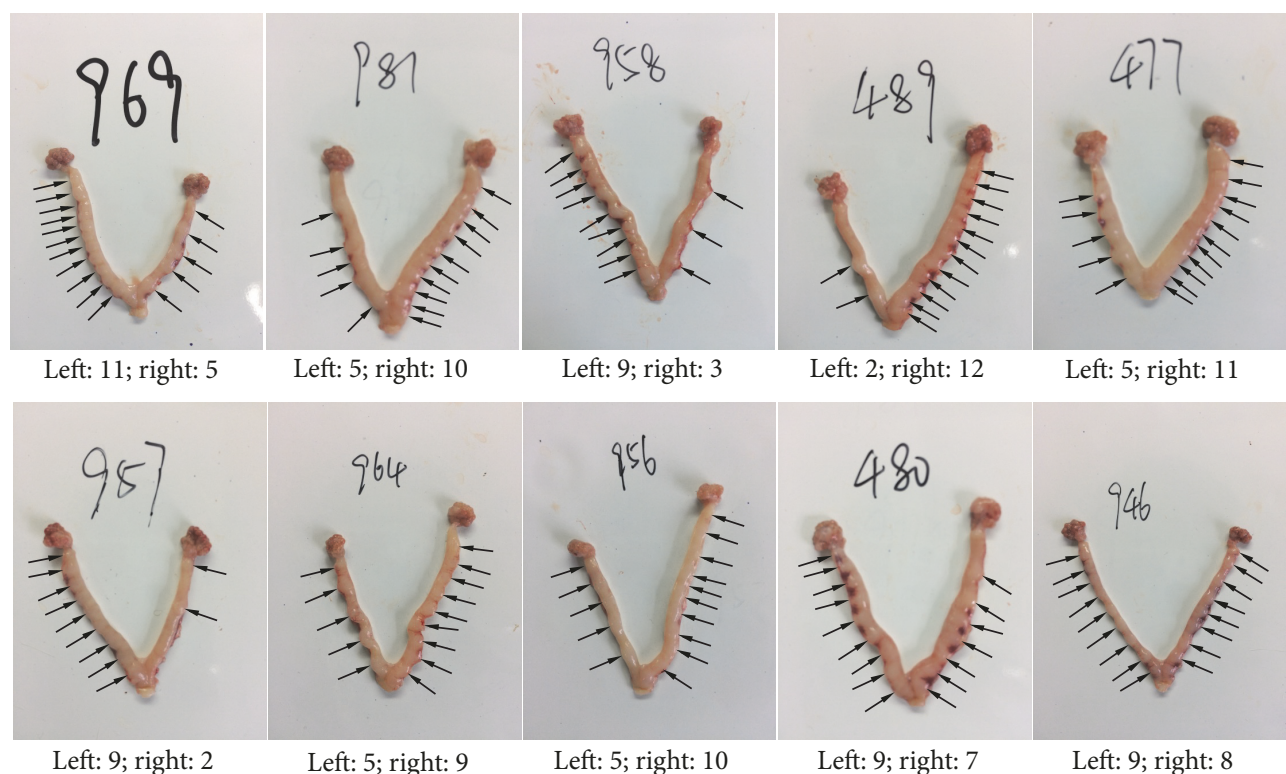

(a)
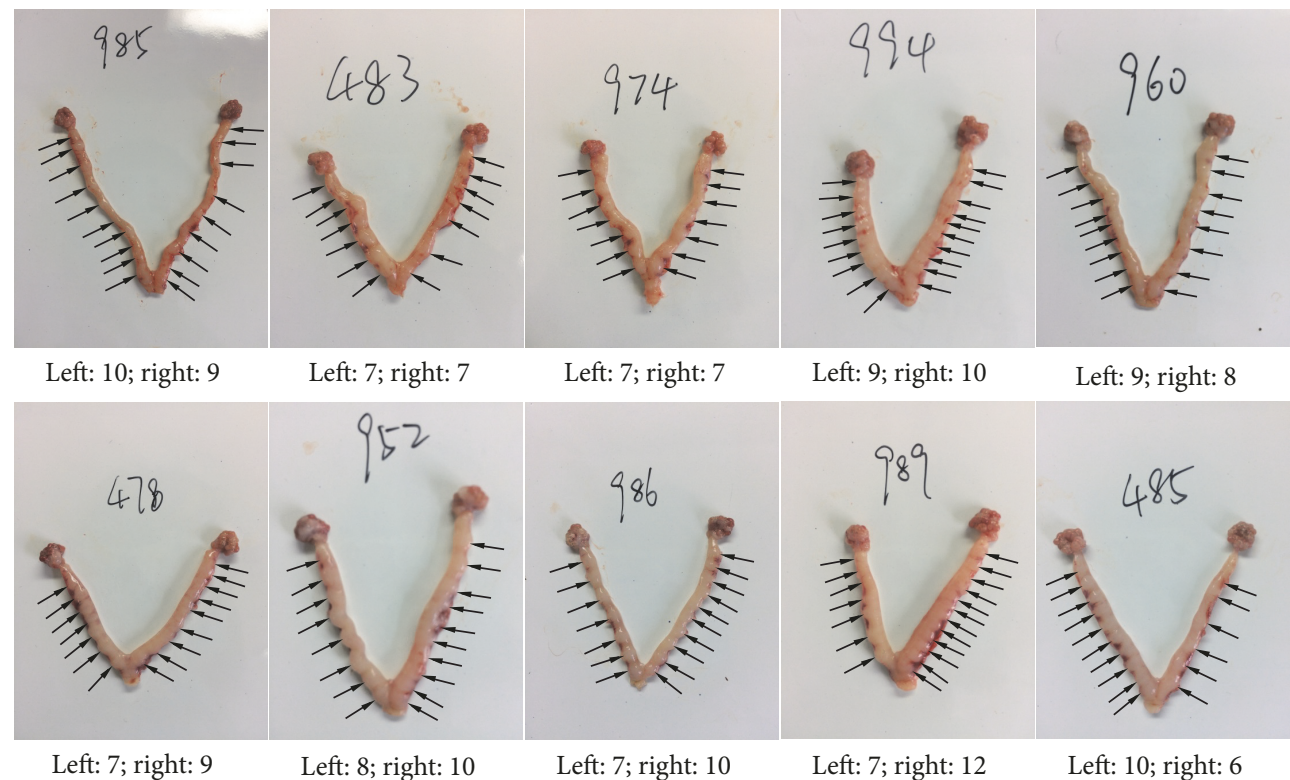

(b)

FIGURE 1: Effect of dietary leucine supplementation on implantation on day 7 of pregnancy in SD rats. Implantation site distributions in control (a) and leucine (b) group. 


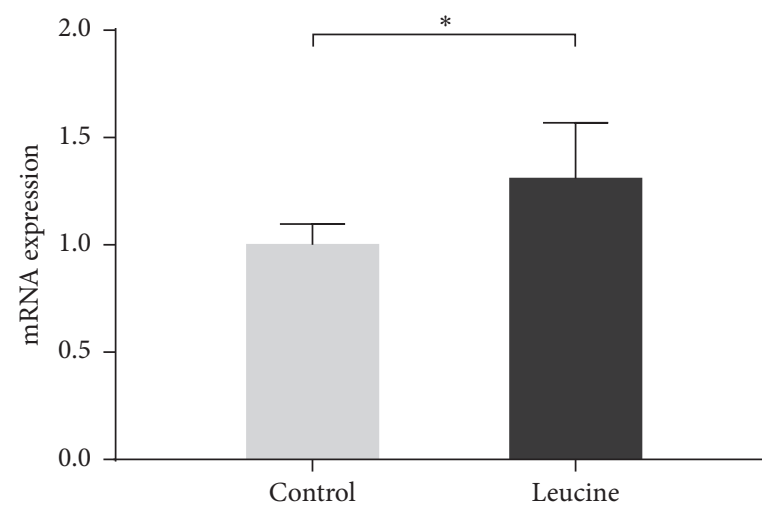

(a)

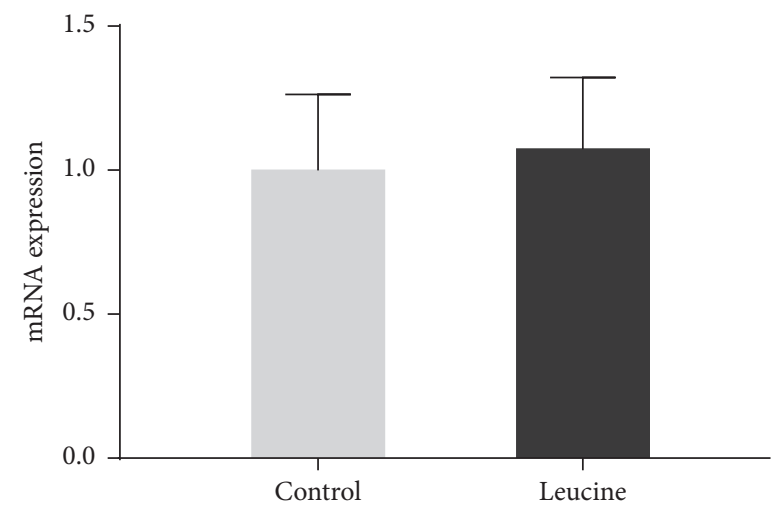

(c)

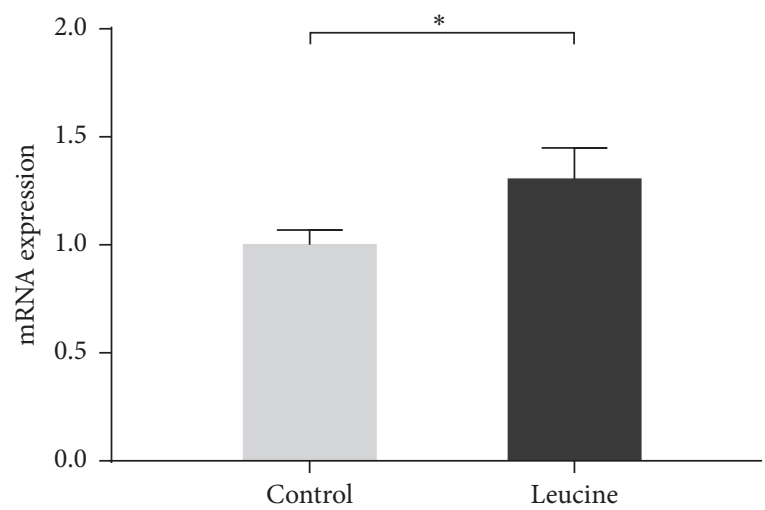

(e)

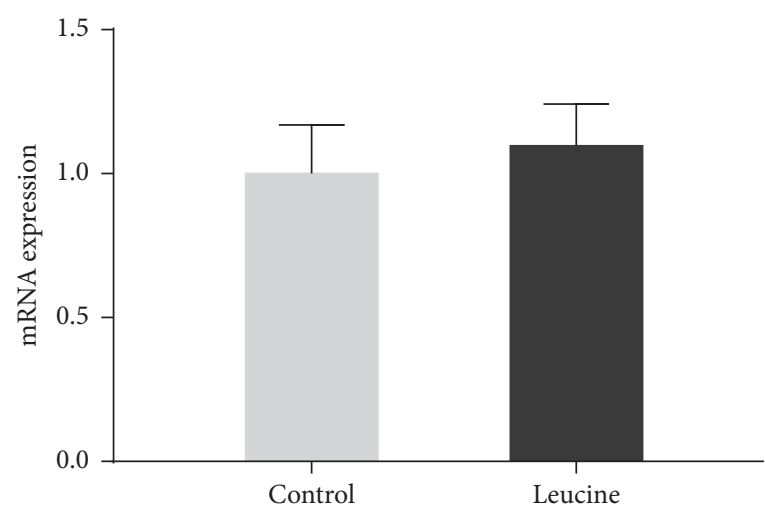

(b)

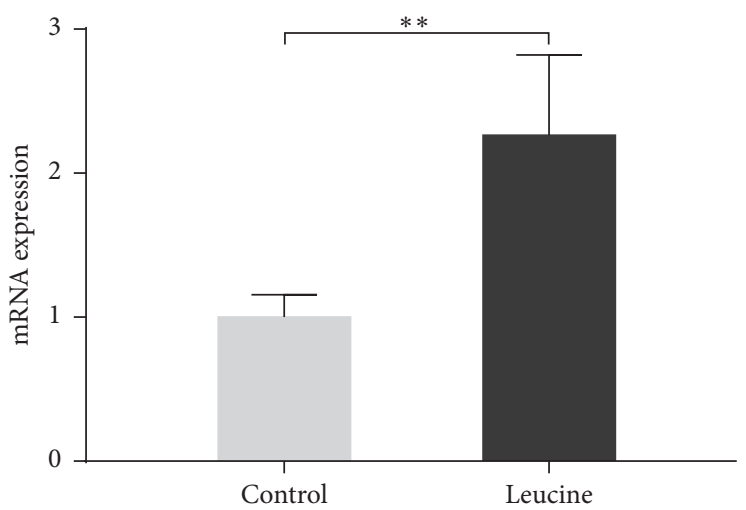

(d)

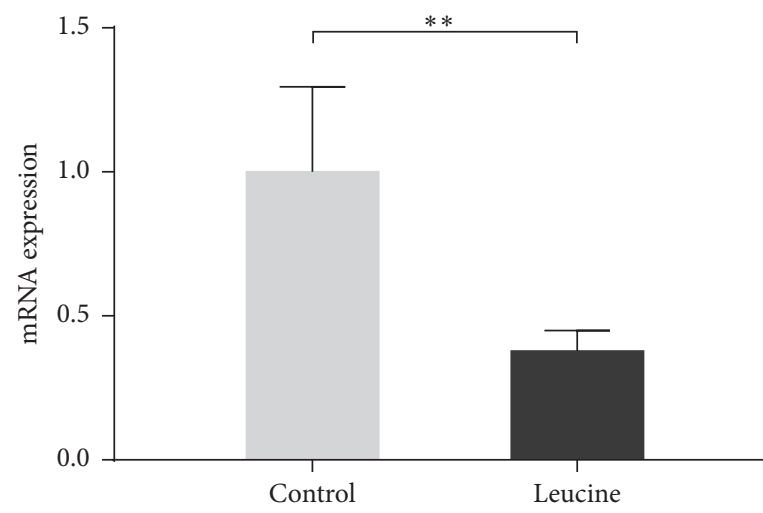

(f)

FIGURE 2: Effect of dietary leucine supplementation on the expression of gene involved in ovarian receptivity on day -1 of pregnancy in SD rats. The gene expression levels of LHR (a), FSHR (b), CYP17A1 (c), CYP19A1 (d), VEGFA (e), and Mucin-1 (f) in ovary on day -1 of pregnancy were measured by quantitative real-time PCR. Data is expressed as mean \pm standard error of means of nine replicates. ${ }^{*}$ Labeled with significant difference $(P<0.05) ;{ }^{* *}$ labeled with extreme difference $(P<0.01)$.

TABLE 3: Effect of dietary leucine supplementation on total number of implantation sites on day 7 of pregnancy in primiparous SD rats.

\begin{tabular}{lccc}
\hline Items & Control & $0.6 \%$ leucine & $P$ value \\
\hline $\begin{array}{l}\text { Number of } \\
\text { implantation sites }(n)\end{array}$ & $15.90 \pm 0.69$ & $17.20 \pm 0.49$ & 0.321 \\
\hline
\end{tabular}

Value is the mean \pm standard error of means of ten replicates.

and during the follicular phase seems to have the potential to decrease the within-litter variation in birth weight [26].
It can be speculated that dietary leucine supplementation had a positive function in premating period, likely during follicular growth phase. Specifically, the effects of leucine administration on within-litter birth weight variation could be attributed to its effect on follicle quality and/or oocyte quality [27]. However, as there was no difference in litter size, we suppose that the limited uterine space is another restricted factor of fetal development [28]. Although the absolute weight of the ovary was higher in the leucine group, the relative weight did not differ between these two 
TABLE 4: Effect of dietary leucine supplementation on tissue weights on day -1 of pregnancy in SD rats.

\begin{tabular}{|c|c|c|c|c|c|}
\hline \multirow{3}{*}{ Groups } & \multirow{3}{*}{$\begin{array}{c}\text { Body weight } \\
\text { g }\end{array}$} & \multicolumn{2}{|c|}{ Absolute tissue weight } & \multicolumn{2}{|c|}{ Percentage of BW } \\
\hline & & Ovary & Uterus & Ovary & Uterus \\
\hline & & $\mathrm{mg}$ & $\mathrm{g}$ & \multicolumn{2}{|c|}{$\%$} \\
\hline Control & $271.57 \pm 3.27$ & $125.21 \pm 0.01$ & $0.39 \pm 0.01$ & $0.49 \pm 0.01$ & $1.42 \pm 0.06$ \\
\hline $0.6 \%$ leucine & $276.38 \pm 4.48$ & $141.33 \pm 0.01^{*}$ & $0.42 \pm 0.04^{* *}$ & $0.52 \pm 0.01$ & $1.55 \pm 0.16^{* *}$ \\
\hline
\end{tabular}

Value is the mean \pm standard error of means of ten replicates; $*$ is means labeled with significant difference $(P<0.05)$; ** is means labeled with extreme difference $(P<0.01)$.

TABLE 5: Effect of dietary leucine supplementation on plasma hormones in primiparous SD rats.

\begin{tabular}{|c|c|c|c|}
\hline Items & Control & $0.6 \%$ leucine & $P$ value \\
\hline \multicolumn{4}{|l|}{ Day -1 of pregnancy } \\
\hline Insulin (uIU/mL) & $18.44 \pm 2.95^{*}$ & $14.82 \pm 1.25$ & 0.017 \\
\hline IGF-1 (ng/mL) & $157.90 \pm 10.73$ & $206.43 \pm 33.99^{* *}$ & $\ll 0.01$ \\
\hline Estradiol (pg/mL) & $9.95 \pm 0.97$ & $10.76 \pm 2.12^{*}$ & 0.040 \\
\hline Progesterone (pg/mL) & $406.24 \pm 0.02$ & $431.58 \pm 0.01$ & 0.493 \\
\hline LH (uIU/mL) & $5.32 \pm 0.10$ & $5.87 \pm 0.21^{*}$ & 0.038 \\
\hline $\mathrm{FSH}(\mathrm{uIU} / \mathrm{mL})$ & $4.78 \pm 0.99$ & $6.37 \pm 1.22$ & 0.542 \\
\hline \multicolumn{4}{|l|}{ Day 7 of pregnancy } \\
\hline Insulin (uIU/mL) & $26.04 \pm 1.79$ & $16.40 \pm 1.84$ & 0.937 \\
\hline IGF-1 (ng/mL) & $139.40 \pm 8.39$ & $229.70 \pm 26.39^{* *}$ & $\ll 0.01$ \\
\hline Estradiol (pg/mL) & $5.91 \pm 0.44$ & $7.22 \pm 1.35^{* *}$ & $\ll 0.01$ \\
\hline Progesterone (pg/mL) & $396.20 \pm 0.01$ & $412.97 \pm 0.02^{*}$ & 0.015 \\
\hline $\mathrm{LH}(\mathrm{uIU} / \mathrm{mL})$ & $5.14 \pm 0.19$ & $6.08 \pm 0.13$ & 0.369 \\
\hline $\mathrm{FSH}(\mathrm{uIU} / \mathrm{mL})$ & $6.84 \pm 0.96$ & $7.34 \pm 1.44$ & 0.305 \\
\hline \multicolumn{4}{|l|}{ Day 20 of pregnancy } \\
\hline Insulin (uIU/mL) & $22.47 \pm 1.70$ & $15.63 \pm 1.42$ & 0.617 \\
\hline IGF-1 (ng/mL) & $195.43 \pm 13.64$ & $252.33 \pm 30.15^{*}$ & 0.038 \\
\hline Estradiol (pg/mL) & $39.83 \pm 3.17$ & $43.12 \pm 7.21^{*}$ & 0.032 \\
\hline Progesterone (pg/mL) & $429.65 \pm 0.01$ & $412.68 \pm 0.02$ & 0.424 \\
\hline LH (uIU/mL) & $5.30 \pm 0.28$ & $5.60 \pm 0.32$ & 0.671 \\
\hline FSH (uIU/mL) & $11.01 \pm 1.16$ & $4.67 \pm 0.55^{*}$ & 0.049 \\
\hline
\end{tabular}

Value is the mean \pm standard error of means of ten replicates; $*$ is means labeled with significant difference $(P<0.05) ; * *$ is means labeled with extreme difference $(P<0.01)$.

TABLE 6: Effect of dietary leucine supplementation on plasma and liver antioxidant enzyme activity and oxidant products on day -1 of pregnancy in SD rats.

\begin{tabular}{lccc}
\hline Items & Control & $0.6 \%$ leucine & $P$ value \\
\hline Plasma & & & $\ll 0.01$ \\
SOD $(\mathrm{U} / \mathrm{mL})$ & $51.29 \pm 2.60$ & $63.02 \pm 2.10^{* *}$ & 0.037 \\
CAT $(\mathrm{U} / \mathrm{mL})$ & $40.76 \pm 3.36$ & $48.66 \pm 7.47^{*}$ & 0.032 \\
GSH-Px $(\mathrm{U} / \mathrm{mL})$ & $848.58 \pm 31.71$ & $897.71 \pm 43.12^{*}$ & 0.56 \\
MDA $(\mathrm{nmol} / \mathrm{ml})$ & $5.05 \pm 0.53$ & $6.34 \pm 0.65$ & 0.483 \\
Liver & & & 0.019 \\
SOD $(\mathrm{U} / \mathrm{mL})$ & $61.23 \pm 5.97$ & $76.66 \pm 7.71$ & 0.170 \\
CAT $(\mathrm{U} / \mathrm{mL})$ & $53.52 \pm 3.20$ & $58.66 \pm 1.29^{*}$ & 0.143 \\
GSH-Px $(\mathrm{U} / \mathrm{mL})$ & $611.10 \pm 34.63$ & $684.70 \pm 20.78$ & $2.78 \pm 0.11$ \\
MDA $(\mathrm{nmol} / \mathrm{ml})$ & $2.90 \pm 0.18$ & & $0.05)$ \\
\hline
\end{tabular}

Value is the mean \pm standard error of means of nine replicates; $*$ is means labeled with significant difference $(P<0.05)$; ** is means labeled with extreme difference $(P<0.01)$. 


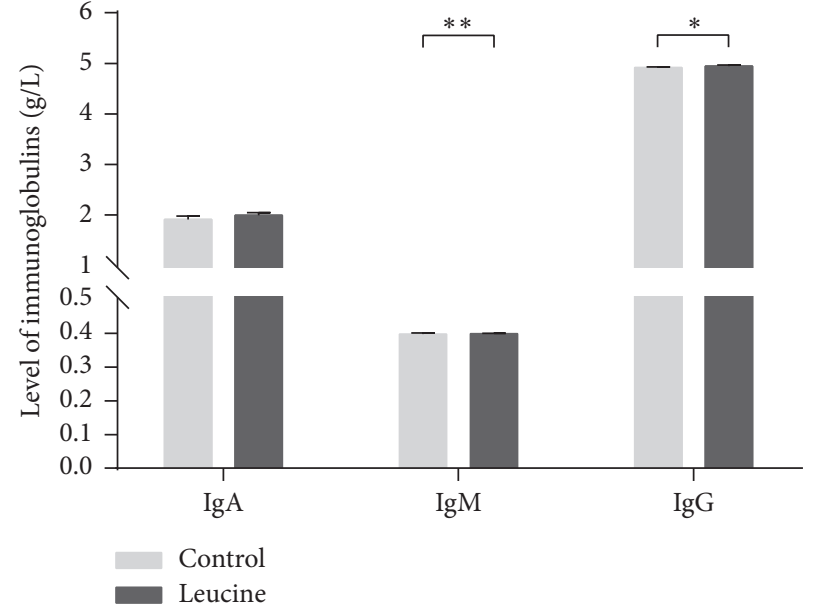

(a)

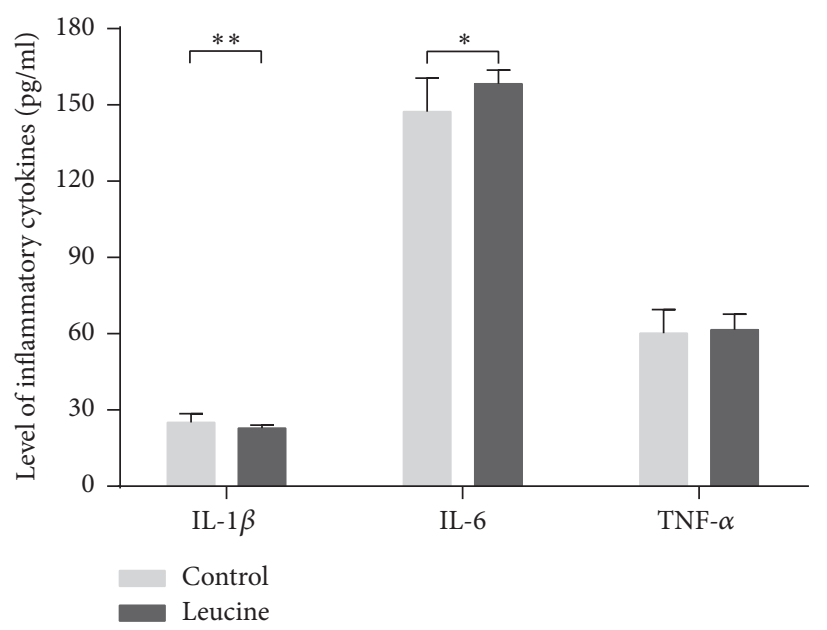

(b)

Figure 3: Effect of dietary leucine supplementation on the level of immunoglobulin (a) and inflammatory cytokines (b) in the plasma on day -1 of pregnancy in SD rats. Data is expressed as mean \pm standard error of means of nine replicates. ${ }^{*}$ Labeled with significant difference $(P<0.05) ;{ }^{* *}$ labeled with extreme difference $(P<0.01)$.

groups. The higher absolute weight of ovary could indicate a better oocyte quality or larger follicular size in the leucine group. In addition, on maternal metabolism level, different plasma metabolites were found between the leucine and control groups. Dams in leucine group showed increased concentration of plasma estradiol accompanied by augment in FSH level, which may be indicator of an upregulation of ovarian response to gonadotropins.

Establishing contact with the endometrium is a challenge for blastocysts during the window of implantation, which requires both competent blastocyst and receptive uterus. However, manifest differences in blastocyst developmental competence lower the successful rate of implantation [5]. Abundant estradiol secreted from advanced embryos stimulates uterine secretions to their own benefit, however, which is detrimental to the less-developed littermate embryos [29, 30]; therefore, considerable embryonic loss occurs in the periimplantation phase. Based on decreased within-litter birth weight variation in the leucine group, the effects of leucine on embryonic implantation were investigated on day 7 of pregnancy. And results have shown that as an aspect of severe asymmetrical distribution of embryos observed in the control group, it could result from absorption of less-competent blastocysts. Like late gestation phase in this study, in the early pregnancy, leucine increased the circulating progesterone concentration as well as IGF-1 and IGF-1-induced steroidogenesis by activating MAPK ERK1/2 phosphorylation [31], which could positively regulate progesterone and estradiol production in cultured rat granulosa cells [32].

Early results suggested that leucine was particularly important for initiation of embryo outgrowth [33]. González et al. [19] removed leucine from the culture medium resulting in quiescent embryos that fail to form trophoblastic outgrowths. In this study, we found higher concentration of estradiol and IGF-1 in rats treated with leucine at all the three-time points during pregnancy. The reason might be that estradiol is the major signal for maternal recognition of pregnancy, especially, which coincides with the time of concepts elongation [34, 35]. Meanwhile, the higher concentration of IGF-1 in the leucine group is in accordance with previous study that demonstrated that the development of follicles and oocytes is improved owing to higher concentration of IGF-1 [36]. Other researches demonstrated that higher IGF1 level during the ovarian follicular phase reduced withinlitter variation in birth weight in the subsequent litter $[27,37]$. In addition, the level of $\mathrm{LH}$ was increased on day -1 of pregnancy in the leucine group. This could be explained by the fact that leucine administration has a positive feedback on the hypothalamus-pituitary axis leading to an increase in gonadotropins release which may act to modulate follicle development. On the other hand, during follicular growth, with the increasing level of $\mathrm{LH}$, recruited follicles can increase the release of estradiol production [38] and therefore further follicular development.

We further evaluated the gene expression which is related to the follicular growth and oocyte maturation. Correspondingly, leucine upregulated expressions of $L H R, C Y P 19 A 1$, and VEGFA genes and downregulated levels of Mucin-1. CYP19A1 is a key gene for steroid synthesizing and plays a critical role in follicle recruitment. In another study, CYP19A1 mRNA had a better expression in the larger follicles (6-9 $\mathrm{mm}$ in diameter), compared with some follicles of $4-6 \mathrm{~mm}$ [39]. Increasing results suggest that VEGFA is regarded as a useful marker of follicle quality [40]. Direct injection of $V E G F$ gene fragments into the ovaries of rats not only increased VEGF mRNA and protein in the ovary, but also resulted in a larger amount of preovulatory follicles with a greater capillary density within the theca layer of treated follicles [41].

During pregnancy, it is known that a certain degree of inflammation is required to ensure successful implantation 
TABLE 7: Effect of dietary leucine supplementation on the concentration of amino acids on day -1 and day 7 of pregnancy in SD rats.

\begin{tabular}{|c|c|c|c|}
\hline Amino acid (ug/ml) & Control & Leucine & $P$ value \\
\hline \multicolumn{4}{|l|}{ Day -1 of pregnancy } \\
\hline Cysteine & $0.58 \pm 0.14$ & $0.41 \pm 0.14$ & 0.882 \\
\hline Phenylalanine & $11.21 \pm 0.49$ & $13.17 \pm 0.89$ & 0.095 \\
\hline Alanine & $32.99 \pm 1.76$ & $45.95 \pm 3.88^{*}$ & 0.027 \\
\hline Glycine & $16.80 \pm 1.52$ & $21.06 \pm 1.97$ & 0.453 \\
\hline Glutamic acid & $17.10 \pm 0.73$ & $21.54 \pm 1.17$ & 0.169 \\
\hline Glutamine & $84.80 \pm 4.82$ & $89.30 \pm 2.16^{*}$ & 0.025 \\
\hline Methionine & $5.60 \pm 0.30$ & $6.97 \pm 0.46$ & 0.217 \\
\hline Arginine & $22.36 \pm 1.94$ & $24.51 \pm 0.79^{*}$ & 0.013 \\
\hline Lysine & $106.49 \pm 8.11$ & $97.99 \pm 5.88$ & 0.353 \\
\hline Tyrosine & $11.08 \pm 1.03$ & $12.10 \pm 0.75$ & 0.358 \\
\hline Leucine & $15.89 \pm 0.60$ & $20.25 \pm 1.42^{*}$ & 0.017 \\
\hline Proline & $15.24 \pm 0.80$ & $19.04 \pm 0.86$ & 0.810 \\
\hline Tryptophan & $17.06 \pm 0.77$ & $19.62 \pm 1.02$ & 0.415 \\
\hline Serine & $19.66 \pm 1.26$ & $23.99 \pm 1.23$ & 0.951 \\
\hline Threonine & $30.58 \pm 2.88$ & $34.45 \pm 2.90$ & 0.981 \\
\hline Aspartic acid & $0.54 \pm 0.04$ & $0.83 \pm 0.15^{* *}$ & $\ll 0.001$ \\
\hline Asparagine & $6.91 \pm 0.47$ & $8.73 \pm 0.41$ & 0.728 \\
\hline Valine & $18.79 \pm 0.97$ & $22.89 \pm 1.27$ & 0.427 \\
\hline Isoleucine & $11.36 \pm 0.47$ & $14.09 \pm 0.94$ & 0.052 \\
\hline Histidine & $6.87 \pm 0.43$ & $8.47 \pm 0.74$ & 0.118 \\
\hline \multicolumn{4}{|l|}{ Day 7 of pregnancy } \\
\hline Cysteine & $0.24 \pm 0.06$ & $0.35 \pm 0.05$ & 0.827 \\
\hline Phenylalanine & $11.57 \pm 0.52$ & $11.85 \pm 0.53$ & 0.861 \\
\hline Alanine & $40.13 \pm 2.45$ & $40.26 \pm 1.21$ & 0.091 \\
\hline Glycine & $20.24 \pm 1.14$ & $20.10 \pm 1.13$ & 0.891 \\
\hline Glutamic acid & $16.68 \pm 1.06$ & $16.88 \pm 0.77$ & 0.485 \\
\hline Glutamine & $77.50 \pm 3.62$ & $75.84 \pm 2.04$ & 0.174 \\
\hline Methionine & $7.04 \pm 0.23$ & $7.13 \pm 0.12$ & 0.090 \\
\hline Arginine & $20.77 \pm 0.60$ & $23.81 \pm 0.81$ & 0.358 \\
\hline Lysine & $79.78 \pm 12.21$ & $108.21 \pm 7.97$ & 0.325 \\
\hline Tyrosine & $10.34 \pm 0.62$ & $11.56 \pm 0.74$ & 0.549 \\
\hline Leucine & $18.44 \pm 0.88$ & $19.97 \pm 0.58$ & 0.347 \\
\hline Proline & $17.47 \pm 0.63$ & $17.40 \pm 0.58$ & 0.919 \\
\hline Tryptophan & $18.98 \pm 1.11$ & $16.65 \pm 0.54$ & 0.086 \\
\hline Serine & $21.26 \pm 0.96$ & $20.75 \pm 0.65$ & 0.374 \\
\hline Threonine & $33.12 \pm 2.70$ & $30.72 \pm 1.40$ & 0.116 \\
\hline Aspartic acid & $0.71 \pm 0.09$ & $0.67 \pm 0.03^{*}$ & 0.019 \\
\hline Asparagine & $7.31 \pm 0.36$ & $7.52 \pm 0.35$ & 0.917 \\
\hline Valine & $21.84 \pm 0.94$ & $24.45 \pm 0.90$ & 0.968 \\
\hline Isoleucine & $13.01 \pm 0.67$ & $13.93 \pm 0.60$ & 0.858 \\
\hline Histidine & $7.89 \pm 0.52$ & $7.90 \pm 0.30$ & 0.185 \\
\hline
\end{tabular}

Value is the mean \pm standard error of means of eight replicates; $*$ is means labeled with significant difference $(P<0.05) ; * *$ is means labeled with extreme difference $(P<0.01)$.

of blastocyst into the maternal endometrium [42]. Plasma inflammatory cytokines were increased by leucine supplementation, which are indicators of the activated immune system. It is possible that the increased $L H R$ concentration, together with IL-1 $\beta$ and IL- 6 levels, could stimulate the expression of VEGF in luteal cells, which may influence concepts development at time of elongation and maternal recognition of pregnancy [6]. Besides, Plasma IgM and IgG were higher in leucine group. It might reflect a suitable physiology of maternal condition of its subsequent reproductive process. 
These results indicated that leucine supplementation might contribute to follicular development and improve oocyte quality. Mucin-1 is decreased during the implantation phase, which provides access for embryo attaching to the uterine epithelium [43]. Nonetheless, available evidences showed that the reduction of Mucin-1 was required to permit embryo attachment in vivo rather than promoting this process [44, 45]. Intriguingly, in the present study, leucine decreased Mucin-1 mRNA expression in ovary on day -1 of pregnancy. Yet, the identity of the mechanism remained elusive.

Oxidative stress has adverse effect on the developmental competence of oocyte [46], and antioxidant enzymes are proposed as potential indicators for monitoring of oocyte oxidative stress. The increase in SOD, CAT, and GSH-Px levels, as a result of leucine supplementation in this study, partly reflected amelioration in ovarian oxidative stress on day -1 of pregnancy.

In our previous study, arginine has been shown to enhance implantation sites, embryonic survival, and pregnancy outcome [47]. It has been argued that glutamine becomes the principal energy source when the glucose carbons are mainly used for synthesis of cell building blocks in proliferating cell [48]; notably, preimplantation conceptuses follow the aerobic glycolysis-glutaminolysis pattern [49]. Importantly, leucine, as one of the branched chain amino acids (BCAAs), is the substrate for the synthesis of glutamate and arginine in the metabolic pathway of amino acids $[50,51]$. Correspondingly, in the current study, glutamine and arginine concentrations in plasma on day -1 of pregnancy were higher in leucine group. Maternal nutrition via mTOR signaling likely impacts on embryogenesis [52], which indicated that, through mTOR signaling pathway, leucine and glutamine might regulate intracellular protein turnover, therefore affecting the survival and growth of embryos and fetuses $[47,52]$.

\section{Conclusions}

In conclusion, our study not only points toward how leucine supplementation in premating diet increases litter homogeneity but also improves oocyte maturation and quality as well as embryo implantation. This is also the first study, to our knowledge, to demonstrate that leucine administration could reduce within-litter birth weight variation. Furthermore, leucine also increased the maternal antioxidant capacity and immune function, which could partly explain the better reproductive performance in leucine supplemented group. Our results provided much innovative information regarding approaches to mitigate variation of littermate birth weights, which could, in turn, improve neonatal survival.

\author{
Abbreviations \\ BCAAs: Branched chain amino acids \\ CAT: Catalase \\ CYP17A1: Cytochrome p450 family 17 subfamily A \\ polypeptide 1 \\ CYP19A1: Cytochrome p450 family 19 subfamily A \\ polypeptide 1
}

FSH: Follicle stimulating hormone

FSHR: Follicle stimulating hormone receptor

GSH-Px: Glutathione peroxidase

IGF-1: Insulin- like growth factor 1

IgA: Immunoglobulins A

IgG: Immunoglobulins G

IgM: Immunoglobulins $\mathrm{M}$

IL-1 $\beta$ : Interleukins- $1 \beta$

IL-6: $\quad$ Interleukins-6

LH: Luteinizing hormone

LHR: Luteinizing hormone receptor

MDA: Malondialdehyde

SOD: Superoxide dismutase

TNF $\alpha$ : Tumor necrosis factor $\alpha$

VEGFA: Vascular endothelial growth factor A.

\section{Data Availability}

The data used to support the findings of this study are available from the corresponding author upon request.

\section{Conflicts of Interest}

The authors declare that they have no conflicts of interest.

\section{Acknowledgments}

This study was financially supported by the National Key Research and Development Program of China (2016YFD0500506), the Beijing Municipal Natural Science Foundation (no. S170001), the National Natural Science Foundation of China (nos. 31272449, 31422052, 31630074, and L1522030), the China Agriculture Research System (CARS-35), the "111" Project (B16044), Jinxinnong Animal Science Developmental Foundation, and Hunan CoInnovation Center of Animal Production Safety, CICAPS.

\section{Supplementary Materials}

The specific primer sequences used in this study are shown in the Table S1. (Supplementary Materials)

\section{References}

[1] N. Quiniou, J. Dagorn, and D. Gaudré, "Variation of piglets' birth weight and consequences on subsequent performance," Livestock Production Science, vol. 78, no. 1, pp. 63-70, 2002.

[2] S. P. Paredes, A. J. M. Jansman, M. W. A. Verstegen et al., "Analysis of factors to predict piglet body weight at the end of the nursery phase," Journal of Animal Science, vol. 90, no. 9, pp. 3243-3251, 2012.

[3] S. L. Douglas, S. A. Edwards, E. Sutcliffe, P. W. Knap, and I. Kyriazakis, "Identification of risk factors associated with poor lifetime growth performance in pigs," Journal of Animal Science, vol. 91, no. 9, pp. 4123-4132, 2013.

[4] H. Quesnel, L. Brossard, A. Valancogne, and N. Quiniou, "Influence of some sow characteristics on within-litter variation of piglet birth weight," Animal, vol. 2, no. 12, pp. 1842-1849, 2008. 
[5] R. D. Geisert, J. J. Whyte, A. E. Meyer et al., "Rapid conceptus elongation in the pig: An interleukin 1 beta 2 and estrogenregulated phenomenon," Molecular Reproduction and Development, vol. 84, no. 9, pp. 760-774, 2017.

[6] C. L. A. Da Silva, B. Laurenssen, E. Knol, B. Kemp, and N. Soede, "Validation of transrectal ultrasonography for assessment of corpora lutea characteristics in pregnant sows and its relationship with litter characteristics at birth," Translational Animal Science, 2017.

[7] R. L. Krisher, "The effect of oocyte quality on development," Journal of Animal Science, vol. 82, no. 13, pp. E14-E23, 2004.

[8] C. C. Maganhin, R. S. Simões, L. F. P. Fuchs et al., "Melatonin influences on steroidogenic gene expression in the ovary of pinealectomized rats," Fertility and Sterility, vol. 102, no. 1, pp. 291-298, 2014.

[9] A. P. Goud, P. T. Goud, M. P. Diamond, B. Gonik, and H. M. Abu-Soud, "Reactive oxygen species and oocyte aging: Role of superoxide, hydrogen peroxide, and hypochlorous acid," Free Radical Biology \& Medicine, vol. 44, no. 7, pp. 1295-1304, 2008.

[10] H. Tamura, A. Takasaki, I. Miwa et al., "Oxidative stress impairs oocyte quality and melatonin protects oocytes from free radical damage and improves fertilization rate," Journal of Pineal Research, vol. 44, no. 3, pp. 280-287, 2008.

[11] S. A. Robertson and L. M. Moldenhauer, "Immunological determinants of implantation success," The International Journal of Developmental Biology, vol. 58, no. 2-4, pp. 205-217, 2014.

[12] L. M. Christian, "Stress and Immune Function During Pregnancy: An Emerging Focus in Mind-Body Medicine," Current Directions in Psychological Science, vol. 24, no. 1, pp. 3-9, 2015.

[13] D. J. Ham, M. K. Caldow, G. S. Lynch, and R. Koopman, "Leucine as a treatment for muscle wasting: A critical review," Clinical Nutrition, vol. 33, no. 6, pp. 937-945, 2014.

[14] D. W. Gietzen, S. Hao, and T. G. Anthony, "Mechanisms of food intake repression in indispensable amino acid deficiency," Annual Review of Nutrition, vol. 27, pp. 63-78, 2007.

[15] C. J. Lynch, H. L. Fox, T. C. Vary, L. S. Jefferson, and S. R. Kimball, "Regulation of amino acid-sensitive TOR signaling by leucine analogues in adipocytes," Journal of Cellular Biochemistry, vol. 77, no. 2, pp. 234-251, 2000.

[16] G. F. R. Teodoro, D. Vianna, F. T.-L. Leonardo et al., "Leucine is essential for attenuating fetal growth restriction caused by a protein- restricted diet in rats," Journal of Nutrition, vol. 142, no. 5, pp. 924-930, 2012.

[17] S. Zhang, X. Zeng, M. Ren, X. Mao, and S. Qiao, "Novel metabolic and physiological functions of branched chain amino acids: A review," Journal of Animal Science and Biotechnology, vol. 8, no. 1, article no. 10, 2017.

[18] L. J. Van Winkle, "Amino acid transport regulation and early embryo development," Biology of Reproduction, vol. 64, no. 1, pp. $1-12,2001$.

[19] I. M. González, P. M. Martin, C. Burdsal et al., "Leucine and arginine regulate trophoblast motility through mTORdependent and independent pathways in the preimplantation mouse embryo," Developmental Biology, vol. 361, no. 2, pp. 286300, 2012.

[20] G. Wu and C. J. Meininger, "Analysis of Citrulline, Arginine, and Methylarginines Using High-Performance Liquid Chromatography," Methods in Enzymology, vol. 440, pp. 177-189, 2008.
[21] Z. Dai, Z. Wu, S. Jia, and G. Wu, "Analysis of amino acid composition in proteins of animal tissues and foods as precolumn o-phthaldialdehyde derivatives by HPLC with fluorescence detection," Journal of Chromatography B, vol. 964, pp. 116127, 2014.

[22] T. D. Schmittgen and K. J. Livak, "Analyzing real-time PCR data by the comparative CT method," Nature Protocols, vol. 3, no. 6, pp. 1101-1108, 2008.

[23] T.-L. Yuan, Y.-H. Zhu, M. Shi et al., "Within-litter variation in birth weight: impact of nutritional status in the sow," Journal of Zhejiang University SCIENCE B, vol. 16, no. 6, pp. 417-435, 2015.

[24] E. Sell-Kubiak, P. Bijma, E. F. Knol, and H. A. Mulder, "Comparison of methods to study uniformity of traits: Application to birth weight in pigs," Journal of Animal Science, vol. 93, no. 3, pp. 900-911, 2015.

[25] E. M. Ferguson, J. Slevin, S. A. Edwards, M. G. Hunter, and C. J. Ashworth, "Effect of alterations in the quantity and composition of the pre-mating diet on embryo survival and foetal growth in the pig," Animal Reproduction Science, vol. 96, no. 1-2, pp. 89103, 2006.

[26] H. Van Den Brand, L. C. M. Van Enckevort, E. M. Van Der Hoeven, and B. Kemp, "Effects of dextrose plus lactose in the sows diet on subsequent reproductive performance and within litter birth weight variation," Reproduction in Domestic Animals, vol. 44, no. 6, pp. 884-888, 2009.

[27] H. Van Den Brand, N. M. Soede, and B. Kemp, "Supplementation of dextrose to the diet during the weaning to estrus interval affects subsequent variation in within-litter piglet birth weight," Animal Reproduction Science, vol. 91, no. 3-4, pp. 353-358, 2006.

[28] K. A. Vonnahme, M. E. Wilson, G. R. Foxcroft, and S. P. Ford, "Impacts on conceptus survival in a commercial swine herd," Journal of Animal Science, vol. 80, no. 3, pp. 553-559, 2002.

[29] J. L. Vallet, A. K. McNeel, G. Johnson, and F. W. Bazer, “Triennial Reproduction Symposium: Limitations in uterine and conceptus physiology that lead to fetal losses," Journal of Animal Science, vol. 91, no. 7, pp. 3030-3040, 2013.

[30] C. L. A. Da Silva, H. Van Den Brand, B. F. A. Laurenssen et al., "Relationships between ovulation rate and embryonic and placental characteristics in multiparous sows at 35 days of pregnancy," Animal, vol. 10, no. 7, pp. 1192-1199, 2016.

[31] M. Reverchon, M. Cornuau, C. Ram, F. Guerif, D. Royre, and J. Dupont, "Chemerin inhibits IGF-1-induced progesterone and estradiol secretion in human granulosa cells," Human Reproduction, vol. 27, no. 6, pp. 1790-1800, 2012.

[32] L. Tosca, P. Froment, P. Solnais, P. Ferré, F. Foufelle, and J. Dupont, "Adenosine 5/-monophosphate-activated protein kinase regulates progesterone secretion in rat granulosa cells," Endocrinology, vol. 146, no. 10, pp. 4500-4513, 2005.

[33] G. Naeslund, "The effect of glucose-, arginine- and leucinedeprivation on mouse blastocyst outgrowth in vitro," Upsala Journal of Medical Sciences, vol. 84, no. 1, pp. 9-20, 1979.

[34] B. Wojciechowicz, G. Kotwica, K. Zglejc, E. Waszkiewicz, and A. Franczak, "Expression of $17 \beta$-hydroxysteroid dehydrogenase and the effects of LH, FSH and prolactin on oestrone and $17 \beta$ oestradiol secretion in the endometrium of pigs during early pregnancy and the oestrous cycle," Reproduction, Fertility and Development, vol. 29, no. 5, pp. 975-984, 2017.

[35] A. Waclawik, M. M. Kaczmarek, A. Blitek, P. Kaczynski, and A. J. Ziecik, "Embryo-maternal dialogue during pregnancy establishment and implantation in the pig," Molecular Reproduction and Development, vol. 84, no. 9, pp. 842-855, 2017. 
[36] E. M. Ferguson, C. J. Ashworth, S. A. Edwards, N. Hawkins, N. Hepburn, and M. G. Hunter, "Effect of different nutritional regimens before ovulation on plasma concentrations of metabolic and reproductive hormones and oocyte maturation in gilts," Reproduction, vol. 126, no. 1, pp. 61-71, 2003.

[37] J. Wang, C. Feng, T. Liu, M. Shi, G. Wu, and F. W. Bazer, "Physiological alterations associated with intrauterine growth restriction in fetal pigs: Causes and insights for nutritional optimization," Molecular Reproduction and Development, vol. 84, no. 9, pp. 897-904, 2017.

[38] A. E. Drummond, "The role of steroids in follicular growth," Reproductive Biology and Endocrinology, vol. 4, article no. 16, 2006.

[39] B. Bao, M. D. Calder, S. Xie et al., "Expression of steroidogenic acute regulatory protein messenger ribonucleic acid is limited to theca of healthy bovine follicles collected during recruitment, selection, and dominance of follicles of the first follicular wave," Biology of Reproduction, vol. 59, no. 4, pp. 953-959, 1998.

[40] V. Babitha, R. P. Panda, V. P. Yadav et al., "Amount of mRNA and localization of vascular endothelial growth factor and its receptors in the ovarian follicle during estrous cycle of water buffalo (Bubalus bubalis)," Animal Reproduction Science, vol. 137, no. 3-4, pp. 163-176, 2013.

[41] T. Shimizu, K. Iijima, K. Miyabayashi et al., "Effect of direct ovarian injection of vascular endothelial growth factor gene fragments on follicular development in immature female rats," Reproduction, vol. 134, no. 5, pp. 677-682, 2007.

[42] A. Schumacher and A. C. Zenclussen, "Effects of heme oxygenase- 1 on innate and adaptive immune responses promoting pregnancy success and allograft tolerance," Frontiers in Pharmacology, vol. 6, article no. 288, 2015.

[43] W. Inyawilert, T.-Y. Fu, C.-T. Lin, and P.-C. Tang, "MicroRNA199a mediates mucin 1 expression in mouse uterus during implantation," Reproduction, Fertility and Development, vol. 26, no. 5, pp. 653-664, 2014.

[44] M. M. Desouza, G. A. Surveyor, R. E. Price et al., "MUC1/ episialin: A critical barrier in the female reproductive tract," Journal of Reproductive Immunology, vol. 45, no. 2, pp. 127-158, 2000.

[45] P. E. Constantinou, M. Morgado, and D. D. Carson, “Transmembrane mucin expression and function in embryo implantation and placentation," Advances in Anatomy, Embryology and Cell Biology, vol. 216, pp. 51-68, 2015.

[46] Y. Li, Z. Zhang, C. He et al., "Melatonin protects porcine oocyte in vitro maturation from heat stress," Journal of Pineal Research, vol. 59, no. 3, pp. 365-375, 2015.

[47] X. Zeng, F. Wang, X. Fan et al., "Dietary arginine supplementation during early pregnancy enhances embryonic survival in rats," Journal of Nutrition, vol. 138, no. 8, pp. 1421-1425, 2008.

[48] S. Mazurek, "Pyruvate kinase type M2: a key regulator of the metabolic budget system in tumor cells," The International Journal of Biochemistry \& Cell Biology, vol. 43, no. 7, pp. 969980, 2011.

[49] M. Jóźwik, M. Jóźwik, A. J. Milewska, F. C. Battaglia, and M. Jóźwik, "Competitive inhibition of amino acid transport in human preovulatory ovarian follicles," Systems Biology in Reproductive Medicine, vol. 63, no. 5, pp. 311-317, 2017.

[50] N. Li, W. Wang, G. Wu, and J. Wang, "Nutritional support for low birth weight infants: Insights from animal studies," British Journal of Nutrition, vol. 117, no. 10, pp. 1390-1402, 2017.

[51] R. Rezaei, W. Wang, Z. Wu, Z. Dai, J. Wang, and G. Wu, "Biochemical and physiological bases for utilization of dietary amino acids by young Pigs," Journal of Animal Science and Biotechnology, vol. 4, no. 1, article no. 7, 2013.

[52] G. Wu, F. W. Bazer, T. A. Cudd, C. J. Meininger, and T. E. Spencer, "Maternal nutrition and fetal development," Journal of Nutrition, vol. 134, no. 9, pp. 2169-2172, 2004. 


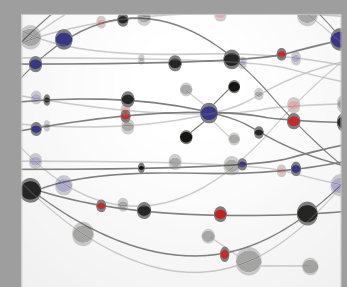

The Scientific World Journal
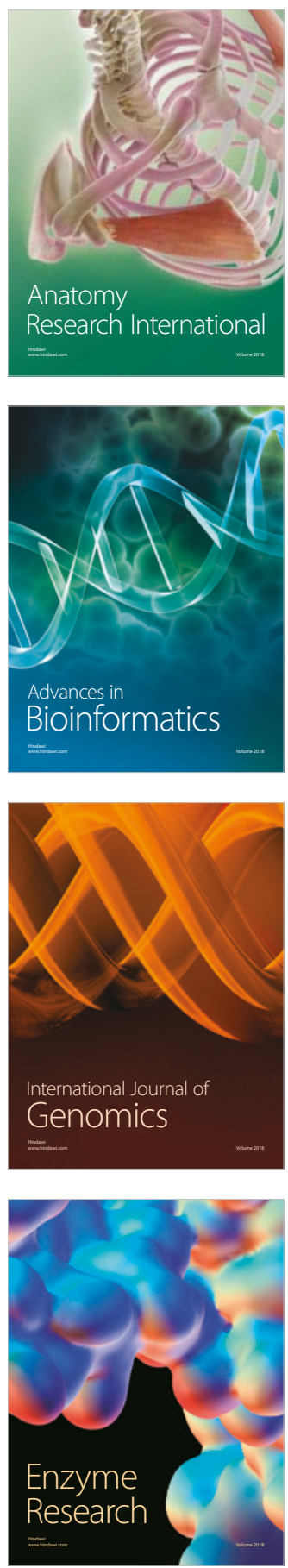
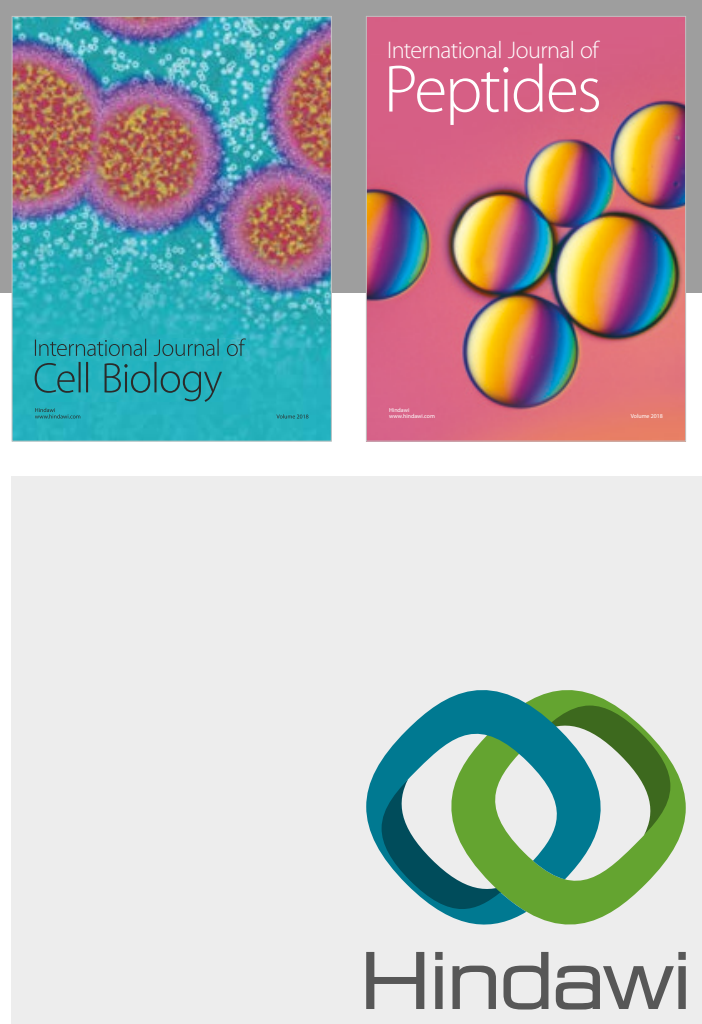

Submit your manuscripts at

www.hindawi.com
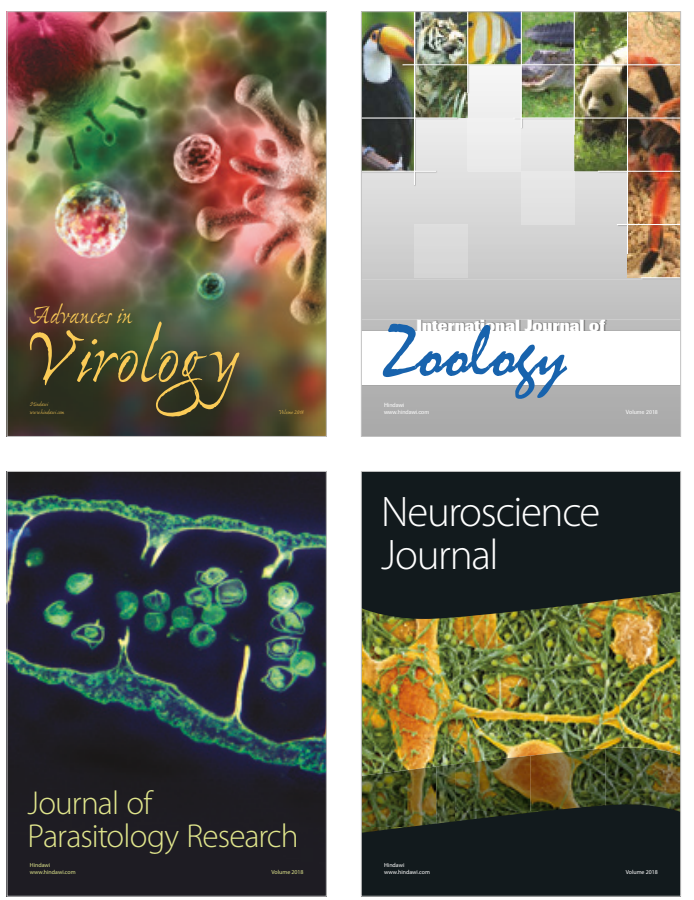
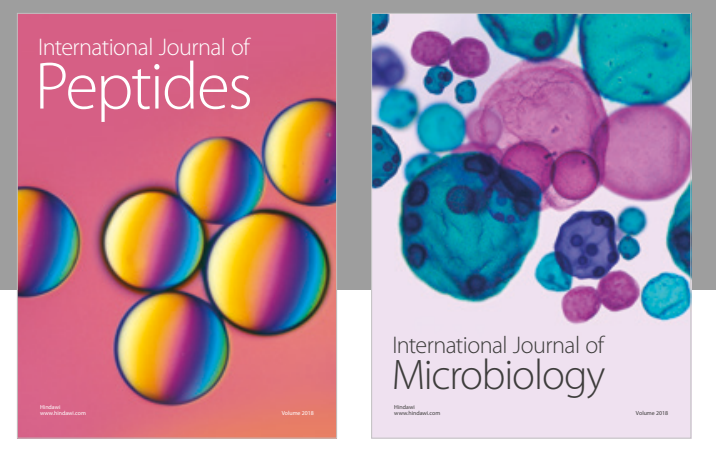

nternational Journal of Microbiology
Journal of
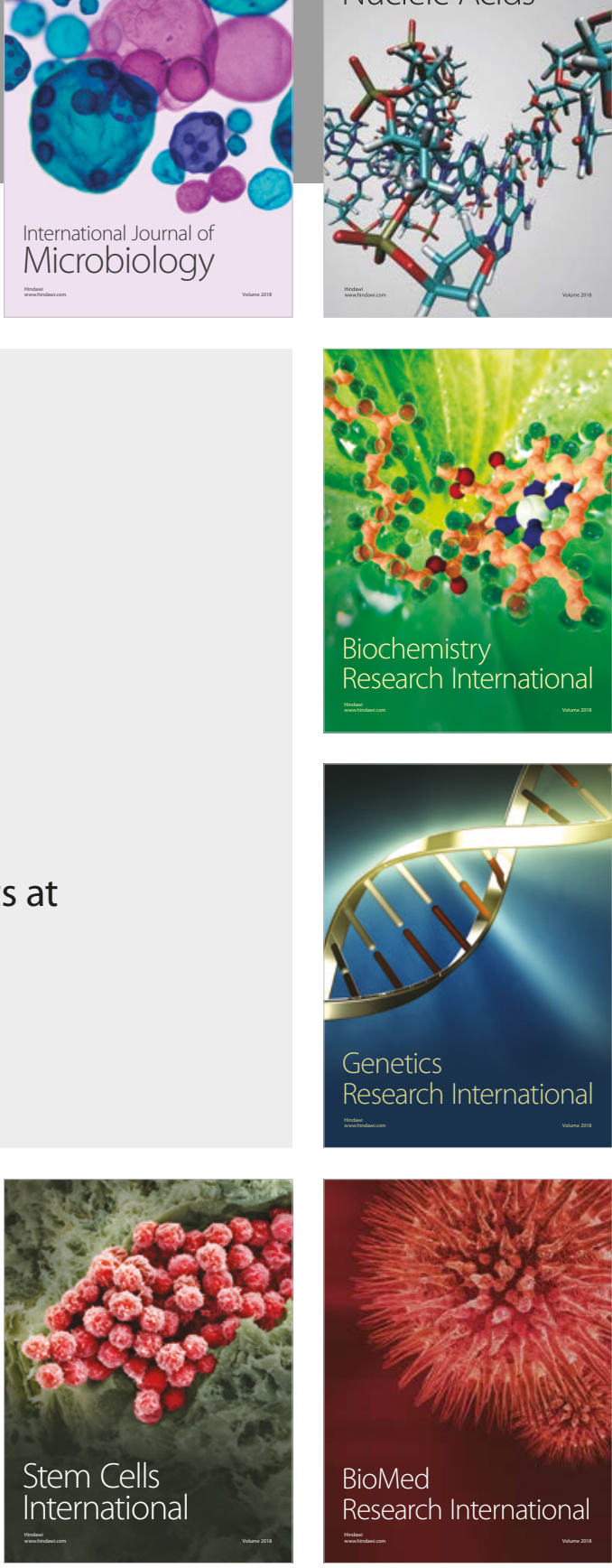
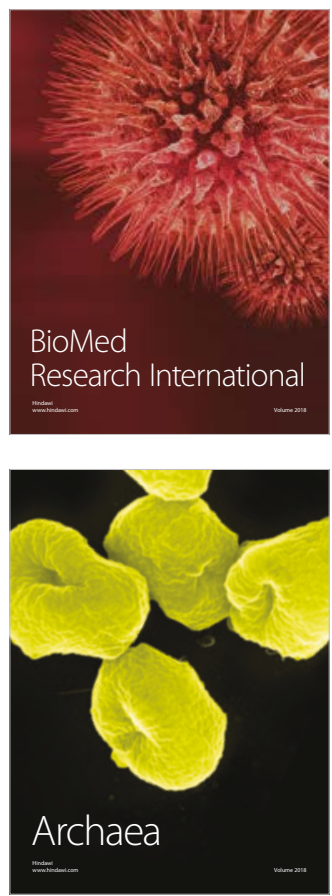